\title{
Efficient RTS and CTS Mechanism Which Save Time and System Resources
}

https://doi.org/10.3991/ijim.v14i04.13243

\author{
Bahaa Kareem Mohammed ${ }^{(凶)}$ \\ Middle Technical University (MTU), Baghdad, Iraq \\ Bahaaka87@gmail.com \\ Saif ali abd alradha Alsaidi \\ Wasit University, Wasit, Iraq \\ Raad Farhood Chisab \\ Middle technical University (MTU), Baghdad, Iraq \\ Haider Th. Salim ALRikabi \\ University of Wasit, Wasit, Iraq
}

\begin{abstract}
It is a well-known fact that the forthcoming names are distinctively different: interference range, career sense, and transmission. The given paper reveals the underlying study of disengagement of a request to send (RTS)/ clear to send (CTS) dialog. It was basically adopted under the influence of both; the presence of distributed coordination function of IEEE 802.11 and a sub-layer protocol which is called media access control (MAC) protocol. The demonstration was seen when applying a type of traffic flows such as Constant Bit Rate (CBR), Transmission Control Protocol (TCP), and besides User Datagram Protocol (UDP). When these are applied the output performance in term of throughput shows a very linear topology configuration of the network. To sum up, a new RTS /CTS mechanism was proposed based on the results obtained from the above suggestions. The detailing for the new mechanism showed that a terminal node will be responsible for deciding if it is authorized to use an RTS/CTS protocol dialog to send one of its packets or not. Needless to say, this process will be dynamic in nature.
\end{abstract}

Keywords-Wireless sensor network, RTS, CTS, UDP, TCP.

\section{Introduction}

The closely placed mobile nodes in an ad-hoc wireless network are the only source of sharing for each of the communications channels [1]. This particular channel's sharing is being taken care of medium access control protocol (MAC) [2]. This protocol is also responsible for determining the efficiency of throughput of the network. A type of protocol, known as dispute based arbitrary access various access protocol is very usually used because of the fact that they are very simple in their implementation process. 
Next, carrier sense based medium access control protocol algorithms are being used which will surely increase the efficiency of the complete operation [3,4]. In this, the packet transmission is attempted only when the mobile terminal is able to determine or sense the idle channel. There is also a possibility of a collision event. This happened when the desired receiver is able to detect multiple transmissions at the same time and such power levels that it becomes very difficult for the receiver to determine which one is meant for the intended receiver [5]. The protocol which is commonly used is the carriers sense multiple access (CSMA)/ collision avoidance (CA). Spatially, when the protocol operation works effectively, then both CSMA/MAC protocols can provide a robust system capability. This off-course requires proper loading levels while working. Induced blocking might lead to masked terminal scenarios because unfortunately the stations might be located in a specific geographical manner [6-9]. Hence, we can summarize to have 2 different problems i.e. hidden terminal and exposed terminal conditions [10].

There are multiple papers already presented which takes care of these problems. In this article, the study was discussed and surveyed the effect of engaging or disengagements for both RTS and CTS methodology based on MAC protocol under the coverage of IEEE 802.11/DCF function [11-12]. In [13] the energy is optimized of 5G networks. of The achievement of linear characteristics of such topology was examined together with and without the RTS/CTS dialogue. The performance differentiation is then made dependent on the achievement of throughput of the different stations [14-16].

\section{Simulation Configuration}

The simulation which was shown in this paper has considered a high number of network loading screenplays along with basic linear topology. The distance that was used to deploy all the nodes from each other was about 250 meters. Thus, every node will be able to reach its next neighbor directly, besides that the negligible processing delay was considered to make the transmission and propagation delays are very well modeled into the system.

In this paper, experiments of four related cases are performed. In each experiment, two types of traffic flow were involved to simultaneously represent the data flow. Figure 1 shows arrows of data flow directions.

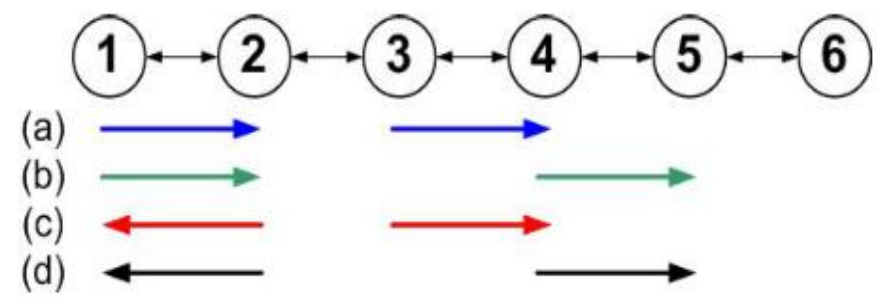

Fig. 1. The screenplay of the system configuration and the grid loading. First hidden terminal topologies (a)-(b), The exposed terminal topologies (c)-(d) 
The throughput performance is evaluated for each of the mentioned scenarios. This is achieved by constant bit rate (CBR) and TCP type traffic. In the former case (CBR type traffic), application layer generates the traffic and it is done in a rate which is more than the capacity of the network so that every packet can be sent again to the back. In the latter case (TCP type traffic), channel utilization is established in the best possible way as it will be allocated automatically and aggressively. The packet size that has been used for both cases was 1460 bytes.

\section{Longer Carrier Sensing Range's Effect}

An extensive simulation was carried out on the analysis use of an easy linear topology as mentioned earlier to disclosure the execution feature of IEEE 802.11/MAC protocol. This work is achieved by adding the usage of user datagram protocol (UDP)/ (CBR) type and TCP type traffic. With the help of these simulations, a conclusion of taking the advantage of an RTS/CTS dialog has been come up and also without using it.

\subsection{Constant Bit Rate (CBR) traffic/UDP}

The flow screenplay for $\{1->2,3->4\}$ is shown in Fig.2. This is split by using RTS/CTS dialog and without using it. It is clearly obvious from the results that these double transmissions occurring simultaneously content with one another so that the total capacity of the channel can be utilized. Also, RTS/CTS dialog can be used to obtain fairness of network if the talk was about the throughput.

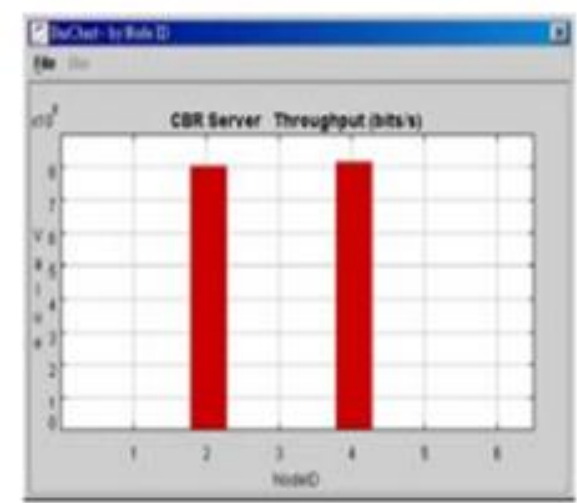

(a) with RTS/CTS

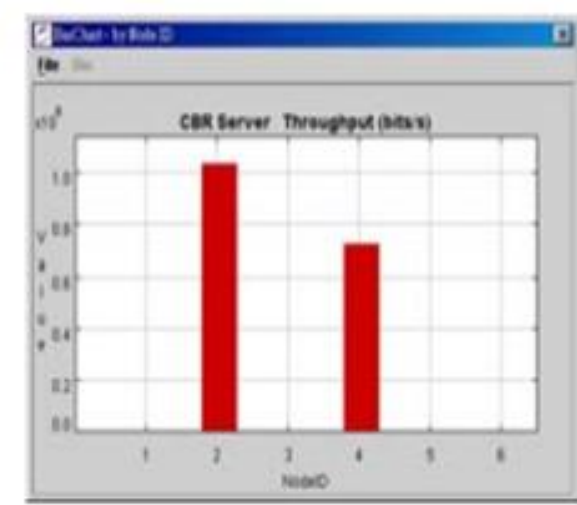

(b) without RTS/CTS

Fig. 2. UDP throughput of $\{1 \rightarrow 2 \rightarrow 3 \rightarrow 4\}$

The throughput scenario for $\{1->2,4->5\}$ is shown in Fig.3. Almost the whole channel is captured by the later. For the previous assumption, the range of transmission was 
approximately equal to the carrier sense range hence these double links will become separate from each other. However, the range of detection of the carrier is a double detection range in reality. In that case, the node number 2 and 4 are able to sense the transmission of each other.

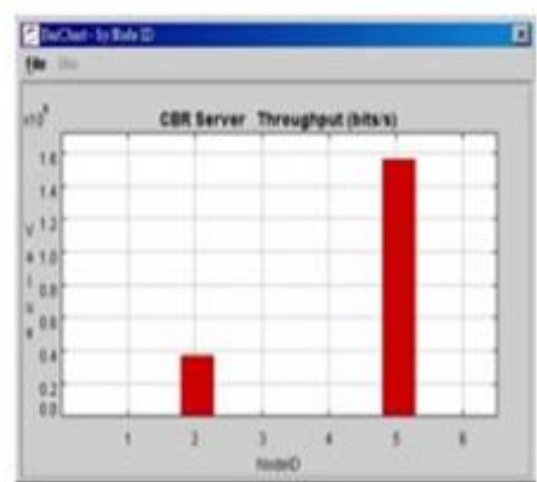

(a) with RTS/CTS

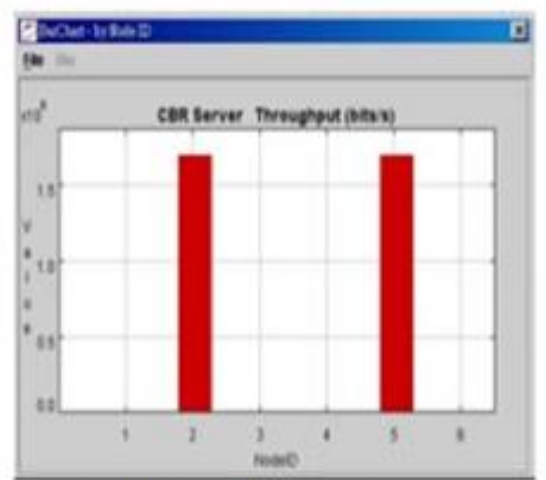

(b) without RTS/CTS

Fig. 3. UDP throughput of $\{1 \rightarrow 2,4 \rightarrow 5\}$

Throughput for exposed terminal topologies is shown in Fig.4 and 5. In the first case, which is $\{2->1,3->4\}$, the node number 2 and 3 are able to hear the transmission for each other. As a result, the mentioned double links shares the full channel capacity and that goes irrespective to the usage of RTS/CTS dialog.

For the scenario $\{2->1,4->5\}$, a higher throughput can be achieved if it is used RTS/CTS dialog and only pure CSMA/CA contention exists between node 2 and 4. Another important point to be noted, the control packets such RTS, CTS will surely help to smooth the flow of data for each link independently but they are not going to help for a contention

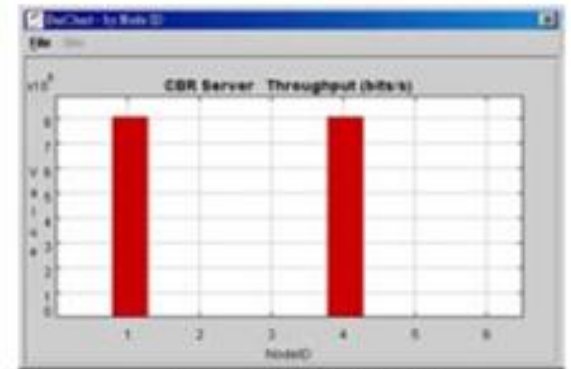

(a) with RTS/CTS

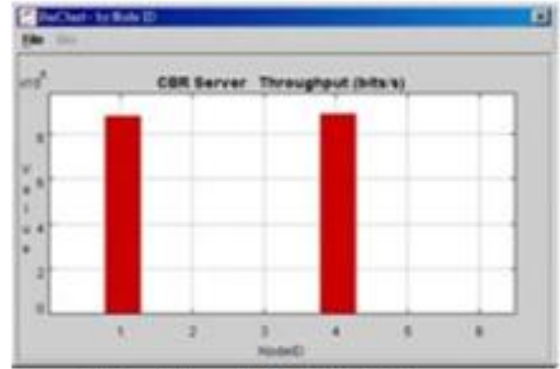

(b) without RTS/CTS

Fig. 4. UDP throughput of $\{2 \rightarrow 1,3 \rightarrow 4\}$ 


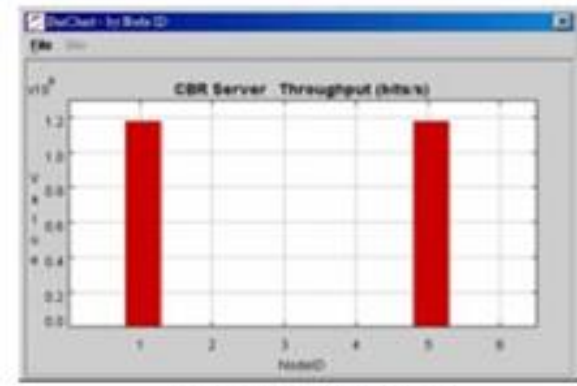

(a) with RTS/CTS

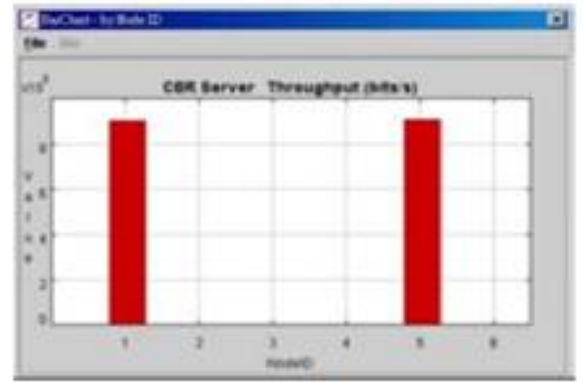

(b) without RTS/CTS

Fig. 5. UDP throughput of $\{2 \rightarrow 1,4 \rightarrow 5\}$

\subsection{TCP file transfer}

To consider a hidden node in our screenplay, node 1 is transferred to the node 2 and node 3 to node 4 so it can be possibly occurring at the same time for both traffic flows which are TCP type traffic.

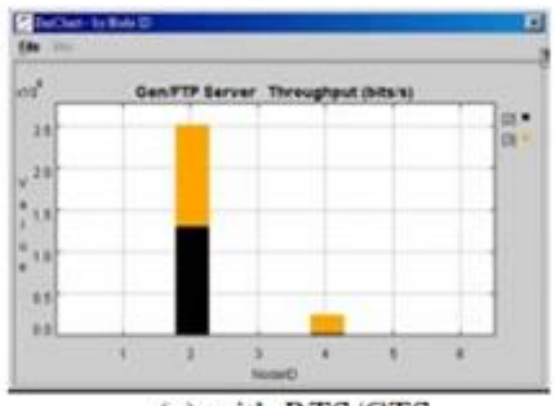

(a) with RTS/CTS

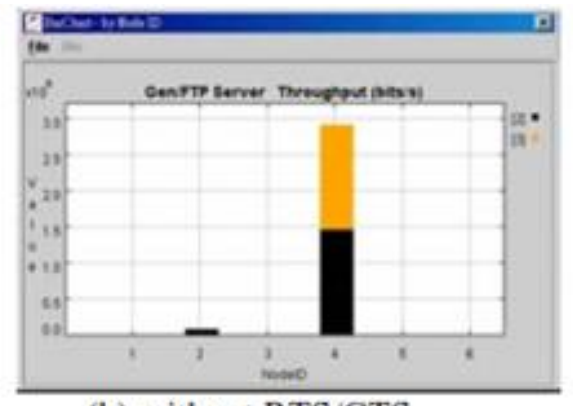

(b) without RTS/CTS

Fig. 6. TCP throughput of $\{2 \rightarrow 1,3 \rightarrow 4\}$

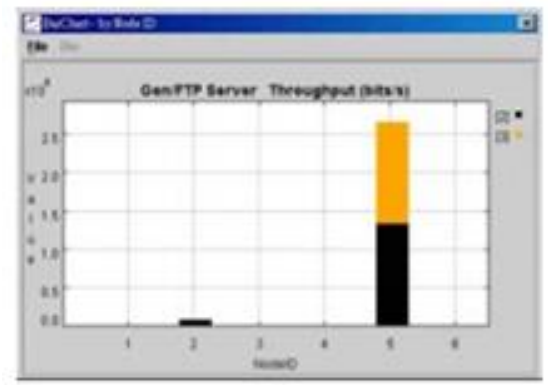

(a) with RTS/CTS

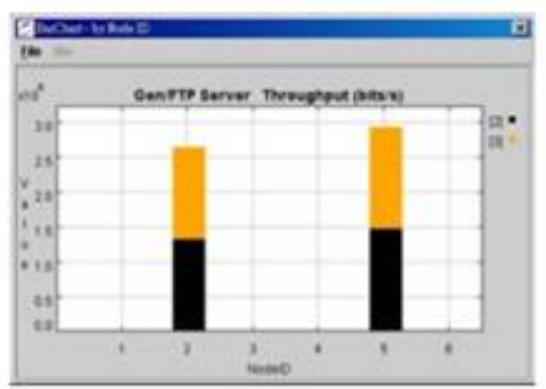

(b) without RTS/CTS

Fig. 7. TCP throughput of $\{1 \rightarrow 2,4 \rightarrow 5\}$. 


\section{Conclusion}

In this paper, the possibility of using RTS/CTS dialog in the MAC protocol of IEEE 802.11 was studied. It was also demonstrated the achievement measurement of a linear topology arrangement inside the network. The performance was measured to explain the influence of using the proposed method. The mechanism of this method showed better improvement in the performance of throughput of CBR traffic flows. Besides that, it presented better patency for the throughput of TCP traffic flows.

Regarding the existing problem of unclearness of throughput which is already caused by IEEE 802.11/ MAC protocol within using RTS/CTS, many studies have investigated the option of adding a mechanism such as TCP to resolve the issue of unclearness. Therefore, a slight modification in MAC sub-layer has been investigated in this study to achieve that goal. The results showed the capability of achieving the performance for UDP and TCP traffic.

\section{$5 \quad$ References}

[1] J. L. Sobrinho and A. S. Krishnakumar, Quality-of-Service in Ad Hoc Carrier Sense Multiple Access Wireless Networks, IEEE JSEC in communications, Aug. 1999. https://doi.org/ $\underline{10.1109 / 49.779919}$

[2] Xu et al, Revealing the Problems with 802.11 Medium Access Protocol in multi-hop wireless ad hoc networks, Computer Networks, 2002. https://doi.org/10.1016/s13891286(01) $\underline{00273-0}$

[3] Raad Farhood Chisab, S. S. Prasad and C. K. Shukla, "A Proposed Improvement Model for Hybrid 3GPP-LTE-OFDMA-DS-CDMA Based on The Multiwavelet Transform”, International Journal of Computer Networking, Wireless and Mobile Communications (IJCNWMC), ISSN 2250-1568, Vol. 3, Issue 1, Mar 2013, 363-374.

[4] Nikolay Tsankov and Ivo Damyanov, "Expertise in the Selection of Electronic Educational Resources - Conceptual Vision”, iJET- Vol. 14, No. 7, 2019, https://doi.org/10.3991/ijet. v14i07.9922, https://www.i-jet.org.

[5] Shenglei Dai, "ARS Interactive Teaching Mode for Financial Accounting Course based on Smart Classroom”, https://doi.org/10.3991/ijet.v14i03.10104, iJET - Vol. 14, No. 3, 2019.

[6] Wenbo Jiang, "Application of 3D Visualization in Landscape Design Teaching. https://doi.org/10.3991/ijet.v14i06.10156, iJET - Vol. 14, No. 6, 2019

[7] Phil Karn, MACA - A New Channel Access Method for Packet Radio, ARRL/CRRL Amateur Radio 9th Computer Networking Conference 1990.

[8] Sun, L.M.; Li, J.Z.; Chen, Y.; Zhu, H.S. Wireless Sensor Networks; Tsinghua Publishing House:

[9] Akyildiz, I.F.; Su, W.; Sankarasubramaniam, Y; Cayirci, E. Wireless sensor networks: a survey. Comput. Networks 2002, 38, 393-422. https://doi.org/10.1016/s13891286(01)00 $\underline{302-4}$

[10] Feng Xia. QoS Challenges and opportunities in wireless sensor/actuator networks. Sensors 2008, 8, 1099-1110. https://doi.org/10.3390/s8021099

[11] Xia, F.; Tian, Y.C.; Li, Y.J.; Sun, Y.X. Wireless sensor/actuator network design for mobile control applications. Sensors 2007, 7, 2157-2173. https://doi.org/10.3390/s7102157 
[12] Chen, J.R.; Kher, S.; Somani, A. Distributed fault detection of wireless sensor networks. In Proceedings of the International Conference on Mobile Computing and Networkings, Los Angeles, CA, USA; ACM: New York, USA, 2006; pp. 65-72.

[13] AlRikabi, Haider Th, et al. "Analysis of the Efficient Energy Prediction for 5G Wireless Communication Technologies." International Journal of Emerging Technologies in Learning 14.8 (2019).

[14] Raad Farhood Chisab and C.K. Shukla, "The Downlink 4G-LTE in Fading Channel Based on the Multiwavelet Transform" IEEE International Conference on Computational Intelligence and Communication Networks (CICN), 14-16 Nov, 2014. Available at: http://ieeexplore.iee.org/document/7065480/. https://doi.org/10.1109/cicn.2014.61

[15] Ibrahim, Isam Aameer, Haider TH Salim, and Hasan F. Khazaal. "Investigating the Analysis of Power Saving Mode in IEEE 802.11 for Wi-Fi Communication." Wasit Journal of Engineering Sciences 6.3 (2018): 13-19. https://doi.org/10.311 85/ejuow.vol6.iss3.100

[16] ALRikabi, Haider Th Salim, Abdul Hadi M. Alaidi, and Faisal Theyab Abed. "Attendance System Design and Implementation Based On Radio Frequency Identification (RFID) And Arduino."

[17] Koushanfar, F.; Potkonjak, M.; Sangiovanni-Vincentelli, A. On-line fault detection of sensor measurements. In Proceedings of the IEEE, Sensors. IEEE Press: Toronto, 2003; Vol. 2, pp. 2224. https://doi.org/10.1109/icsens.2003.1279088

\section{Authors}

Bahaa Kareem Mohammed is working as Lecturer at Department of electrical techniques in Technical institute kut, Middle technical university (MTU)-Iraq Al Kut city -Wasit, Iraq. The number of articles in national databases -1 . The number of articles in international databases - 3. E-mail: Bahaaka87@gmail.com

Saif ali abd alradha alsaidi is a Lecturer at Computer science department, College of education for Pure Science, Wasit university Al Kut city Hay ALRabee, Wasit, Iraq. The number of articles in national databases -2 . The number of articles in international databases - 0. E-mail: salsaidi@uowasit.edu.iq.

Raad Farhood Chisab is a Lecturer at Department of electrical techniques, in Technical institute kut, Middle technical university (MTU)-Iraq, Al Kut city -Wasit, Iraq. The number of articles in national databases -6 . The number of articles in international databases - 8. E-mail: raadfarhood@yahoo.com.

Haider Th. Salim ALRikabi is presently one of the faculty college of engineering, electrical engineering department, Wasit University in Al Kut city, Hay ALRabee, Wasit, Iraq.

He received his B.Sc. degree in Electrical Engineering in 2006 from the Al Mustansiriya University in Baghdad, Iraq. His M.Sc. degree is in Electrical Engineering focusing on Communications Systems from California state university/Fullerton, USA in 2014 .

His current research interests include Communications systems with mobile generation, Control systems, intelligent technologies, smart cities, and Internet of Things (IoT). 
The number of articles in national databases -10 . The number of articles in international databases - 10. Contact: - +9647732212637. E-mail:- hdhiyab@uowasit.edu.iq

Article submitted 2020-01-18. Resubmitted 2020-02-15. Final acceptance 2020-02-16. Final version published as submitted by the authors. 